\title{
ANALISIS HUBUNGAN KETINGGIAN TEMPAT DENGAN JENIS DAN KLASIFIKASI FLORA DI WILAYAH HUTAN SIBOLANGIT
}

\author{
Rena Saputri Hilaria Sitanggang, Khairul Wahyudi, Pastuti Tafonao \\ Jurusan Pendidikan Geografi, Fakultas Ilmu Sosial, Universitas Negeri Medan \\ Email: renasaputri4@gmail.com
}

\begin{abstract}
Abstrak
Daerah penelitian adalah Cagar Alam Sibolangit yang merupakan bagian dari Tahura (taman hutan raya) di sumatera utara. cagar alam sibolangit ini memiliki luas 85,15 Ha. Tujuan penelitian ini adalah 1)mengetahui bagaimana ciri fisik vegetasi flora yang ada di hutan sibolangit, 2) menganalisis klasifikasi jenis flora yang tumbuh dengan suhu dan ketinggian tempat yang berbeda di hutan sibolangit. Teknik pengumpulan data pada penelitian ini menggunakan metode survey lapangan. Survey lapangan digunakan untuk mendapatkan data valid terkait ciri fisik flora untuk klasifikasi flora tersebut. Hasil penelitian menunjukan bahwa jenis flora yang tumbuh di hutan sibolangit sangat beragam dan diklasifikasikan ke dalam 3 filum yaitu: filum spermatophyta, herydophita, dan byrophita. Ketiga jenis filum ini mendominasi pada ketinggian berbeda. Pada ketinggian $700 m$ - 900m filum yang mendominasi adalah spermatophyta dengan kelas Gymnospermae dan angyospermae, ptherophyta, ricciocarpus sp, lycophyta, pada ketinggian $900 m$ - $1100 m$ didominasi filum pheryophyta dengan kelas Pherophyta dan sphenphyta serta lycophyta, angyospermae, bryophyta, hepatophyta dan pada ketinggian $1100 m-1300 m$, didominasi filum byrophyta dengan kelas Bryophyta dan hepatophyta serta rthocerophyta (mendominasi), ptheropchyta, sphenophyta, lycophyta, angyosmpermae.
\end{abstract}

Kata kunci : Ketinggian tempat, Klasifikasi flora, Filum, Kelas.

\begin{abstract}
The research area is Sibolangit Nature Reserve which is part of Tahura (forest park) in north sumatera. sibolangit nature reserve has an area of $85.15 \mathrm{Ha}$. The objectives of this research are 1) to know how the physical characteristics of flora vegetation present in the sibolangite forest, 2) to analyze the classification of flora species that grow with the temperature and height of different places in the sibolangite forest. Data collection techniques in this study using field survey methods. A field survey was used to obtain valid data related to the physical characteristics of the flora for the classification of the florate. The results showed that the type of flora that grows in the forest sibolangit very diverse. And classified into 3 phyla namely: phylum spermatophyta, herydophita, and byrophita. These three types of phyla dominate at different heights. At the height of $700 \mathrm{~m}-900 \mathrm{~m}$ the dominant phylum is spermatophyta with class Gymnospermae and angyospermae, ptherophyta, ricciocarpus sp, lycophyta, at an altitude of $900 m$ - $1100 m$ dominated pheryophyta phyla with class Pherophyta and sphenphyta as well as lycophyta, angyospermae, bryophyta, hepatophyta and at an altitude of $1100 \mathrm{~m}-1300 \mathrm{~m}$, dominated byumhyyta phyla by class Bryophyta and hepatophyta and rthocerophyta (dominate), ptheropchyta, sphenophyta, lycophyta, angyosmpermae.
\end{abstract}

Keywords: Elevation of places, Classification of flora, Phylum, Class.

\section{PENDAHULUAN}

Indonesia dikenal sebagai negara mega-biodiversity dalam hal keanekaragaman hayati, keanekaragaman yang dimiliki tersebar di berbagai wilayah di Indonesia. Indonesia memiliki perbedaan keadaan lingkungan fisik 
sehingga menyebabkan perbedaan karakteristik makhluk hidup. Kemampuan bertahan hidup yang diberikan suatu hutan terhadap mahkluk hidup akan berbeda dengan hutan yang lainnya, sehingga dapat menghasilkan flora atau fauna khas.

Kawasan hutan Provinsi Sumatera Utara seluas \pm 3.055.795 hektar. Kawasan hutan Provinsi Sumatera Utara menurut fungsinya terbagi atas: Kawasan Suaka Alam seluas \pm 427.008 ha, Kawasan Hutan Lindung seluas \pm 1.206 .881 ha, Kawasan Hutan Produksi Terbatas seluas \pm 641.769 ha, Kawasan Hutan Produksi seluas \pm 704.452 ha, Kawasan hutan produksi dapat dikonversi seluas \pm 75.684 hektar (Kementerian Kehutanan, 2014).

Kawasan hutan lindung adalah wilayah yang ditetapkan dengan fungsi utama melindungi kelestarian lingkungan hidup yang mencakup sumberdaya alam dan sumberdaya buatan. Salah satu kawasan konservasi yang tertua yang ada di Indonesia adalah Cagar Alam Sibolangit yang hanya berjarak $38 \mathrm{~km}$ dari kota Medan dan dapat ditempuh sekitar satu jam dengan menggunakan kendaraan umum. Jaraknya yang begitu dekat dengan perkotaan menjadikan kawasan konservasi ini relatif terancam dengan aktivitas manusia. Namun diusianya yang ke-90 saat ini, kawasan Cagar Alam Sibolangit masih terpelihara dengan baik. Daerah ini terletak pada ketinggian antara 246-515 meter dari permukaan laut (mdpl). Bila ditinjau secara geogarfis, kawasan Cagar Alam Sibolangit terletak diantara 30 17' 50"-3: 18' 39" LU dan 98: 36' O"-98: 36'36" BT.

Kawasan hutan sibolangit ini memiliki beragam jenis flora yang tidak banyak berbeda dengan jenis flora yang tersebar di daerah hutan yang beriklim tropis di indonesia khususnya di daerah sumatera. Dan persebaran flora ini tentu dipengarui berbagai faktor seperti halnya faktor suhu dan faktor ketinggian tempat. Perbedaan jenis flora dan ciri ciri flora bisa di amati dengan meninjau ketinggian dari permukaan laut dan suhu rata rata pada ketinggian itu, meski suhu di suatu daerah relatif dan berubah sesuai dengan cuaca maupun musim.

\section{METODE PENELITIAN}

Penelitian ini dilakukan di Desa bandar baru, kecamatan Sibolangit, kabupaten Deli Serdang, Sumatera Utara, Indonesia, berbatasan langsung dengan wilayah Kabupaten Karo. Alat yang digunakan berupa GPS Garmin dan Thermomer digital, Meteran dan bahan yang digunakan adalah peta administrasi kec sibolangit sera peta topografi kec. Sibolangit.

Metode penelitian yang digunakan yaitu metode sampling dengan meneliti hutan sibolangit yang berada di desa bandar baru untuk mewakili populasi yaitu hutan sibolangit. Teknik pengumpulan data yang dilakukan dengan metode survey lapangan. Data yang digunakan dalam penelitian ini adalah kemiringan lereng, klasifikasi vegetasi, variasi ketinggian, dan ciri fisik flora. Selanjutnya data tersebut diolah dengan mengklasifikasikan jenis flora dilihat ciri fisik yang mendominasi pada ketinggian yang berbeda dan menggolongkan kepada kelas dan filum plantae (Tumbuhan). Gambar 1. Peta administrasi kecamatan Sibolangit yang di buat dengan arcGis. 


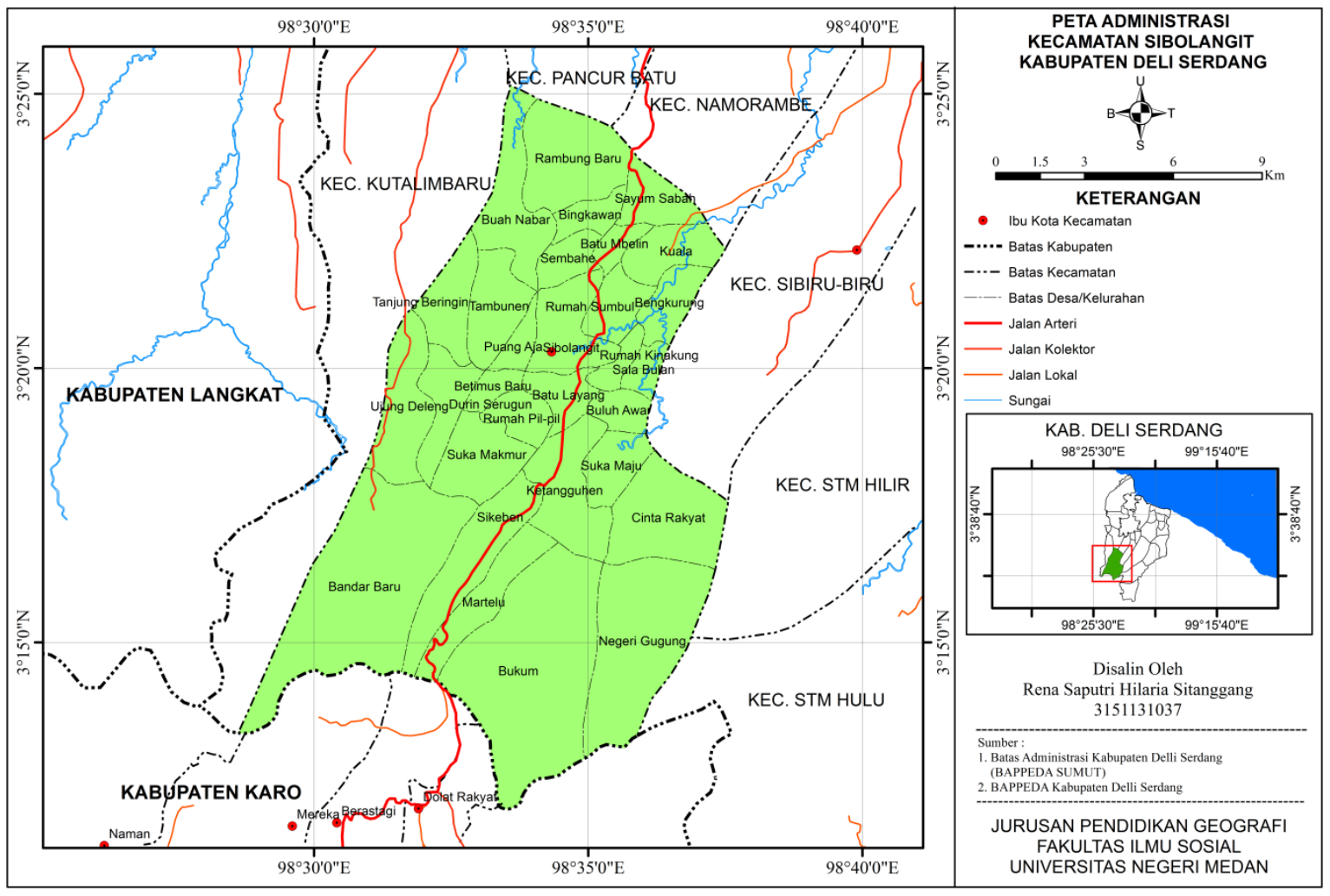

Gambar 1. Peta Administrasi Kecamatan Sibolangit, Kab. Karo, Sumatera Utara

Analisis hasil yang digunakan dalam penelitian ini adalah analisis deskriptif. Secara singkat, tahapan yang dilaksanakan pada penelitian ini dapat dilihat pada gambar 2.

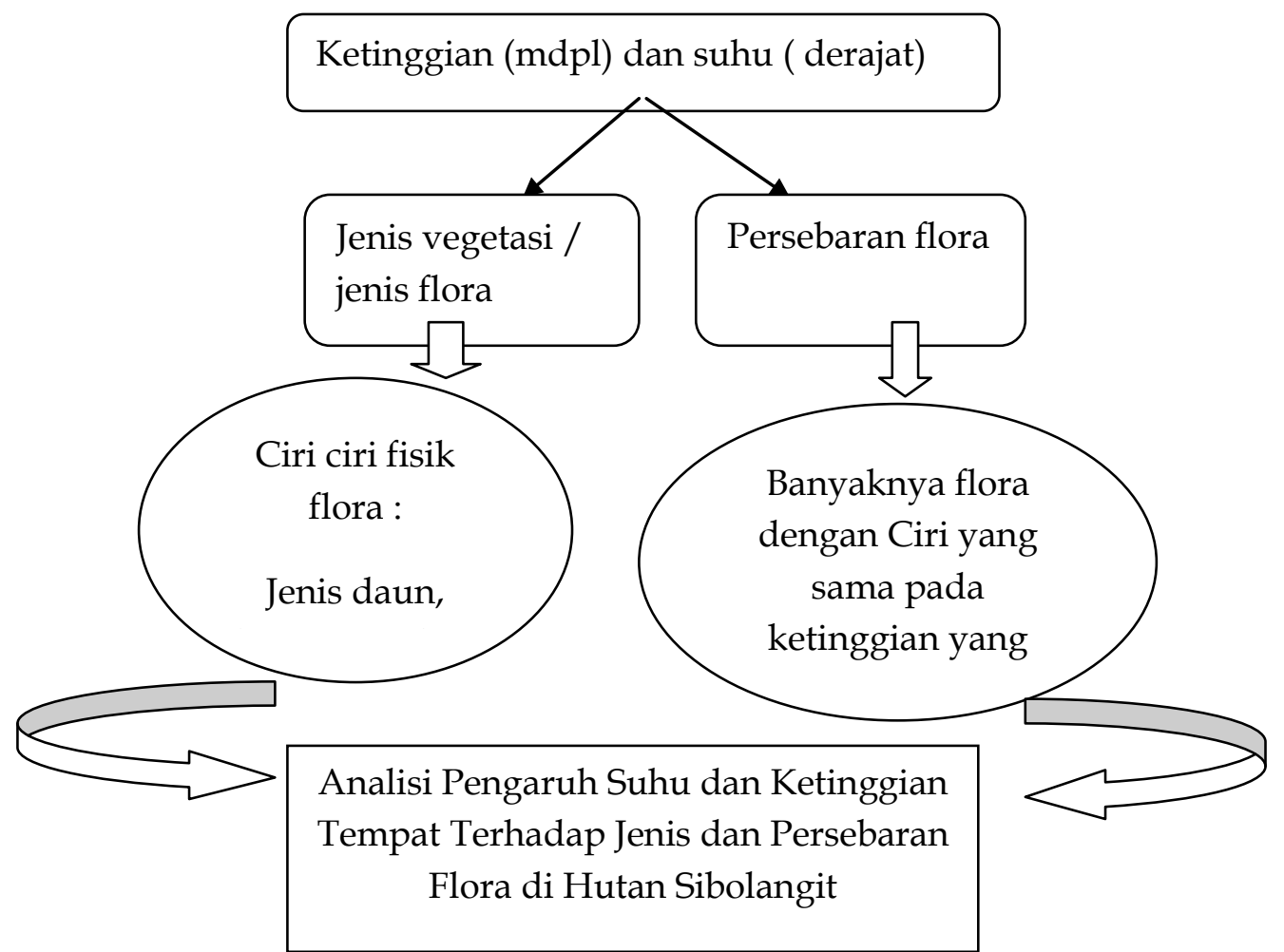




\section{Gambar 2. Tahapan Penelitian}

\section{HASIL DAN PEMBAHASAN}

\section{Karakteristik dan Klasifikasi Flora}

Penelitian ini bertujuan untuk mengetahui karakteristik vegetasi, sesuai perbedaan ketinggian (mdpl) dan perbedaan suhu $\left({ }^{\circ} \mathrm{C}\right)$. Lokasi penelitian berada pada Taman hutan raya sibolangit di desa bandar baru Kecamatan sibolangit Kabupaten karo Pada Tahun 2017. Penelitian didasarkan pengukuran dan observasi langsung di lapangan.

Dari penelitian survei lapangan dengan metode sampling adalah bahwa keadaan ekosistem di hutan Sibolangit terutama persebaran flora di kawasan hutan sibolangit terdapat ribuan jenis tumbuhan dengan beberapa tumbuhan memiliki ciri ciri yang sama dan polapersebaran flora di hutan sibolangit juga mengikuti arus sungai yang ada di kawasan tersebut. Di kawasan tahura sibolangit jenis flora yang tumbuh tidak jauh berbeda dengan jenis flora yang terdapat pada tahura pada umumnya terutama pada tahura yang ada di sumatera. Dan kemiripan jenis flora maupun cenderung sama dengan jenis flora yang terdapat di hutan gunung leuser.
Potensi vegetasi tidak jauh beda dengan yang ada di Kawasan Taman hutan raya Sibolangit, yang didominasi oleh pohon-pohon besar seperti Angsana (Pterocarpus indicus), Nyamplung (Calophyllum inophillum), Meranti (Shorea sp), dll. Juga terdapat jenis tanaman palem dan pinang, durian hutan dan setiap pohon besar juga dominan di tumbuhi tanaman paku. Jenis pada tanaman ini merupakan tanaman umum yang dapat di temui pada hutan tropis di Indonesia. Pengklasifikasan jenis flora di Taman hutan raya sibolangit ini di dasarkan pada kingdom Plantae (Tumbuhan) dan di sesuaikan dengan ona ketinggian (mdpl) di hutan sibolangit. Pengkasifikasian ini di simpulkan sesuai dengan jenis tumbuhan dominan yang diamati pada setiap ketinggian yang berbeda.Jenis flora yang ada di taman hutan raya sibolangit terdiri dari beberapa filum dan kelas yang berbeda yang tercakup dalam satu kingdom yaitu kingdom plantae (Tumbuhan ).

Tabel 1. Klasifikasi Flora Sesuai Ketinggian

\begin{tabular}{|c|c|c|c|c|}
\hline \multirow{2}{*}{ Ona } & \multirow{2}{*}{ Ketinggian } & \multicolumn{2}{|c|}{ Flora yang mendominasi } & \multirow{2}{*}{ Jenis flora } \\
\hline & & Filum & Kelas & \\
\hline $\begin{array}{l}\text { Ona } \\
\text { tropika }\end{array}$ & $\begin{array}{l}500 \\
1000 \mathrm{mdpl}\end{array}$ & Spermatophyta & $\begin{array}{l}\text { Gymnospermae, } \\
\text { angiospermae }\end{array}$ & $\begin{array}{l}\text { Meranti(shorea } \mathrm{sp} \text { ), } \\
\text { beringin, pinang, mahoni, } \\
\text { kuling, sharon, mpyre } \\
\text { (caryota sp) }\end{array}$ \\
\hline $\begin{array}{l}\text { Ona } \\
\text { peralihan }\end{array}$ & $\begin{array}{l}900 \quad- \\
1100 \mathrm{mdpl}\end{array}$ & Pherydophyta & Epifit, liliana & $\begin{array}{l}\text { Anggrek, tumbuhan pakis, } \\
\text { rotan berduri, Luluna (Celtis } \\
\text { sp) }\end{array}$ \\
\hline $\begin{array}{l}\text { Ona } \\
\text { montane }\end{array}$ & $\begin{array}{l}1000 \\
1500 \mathrm{mdpl}\end{array}$ & Bryophyta & $\begin{array}{l}\text { Hepaticeae, } \\
\text { brryopsida }\end{array}$ & $\begin{array}{l}\text { Lumut, kaha (Castanopsis } \\
\text { argentea), Podocarpus, } \\
\text { Elaeocarpus, }\end{array}$ \\
\hline
\end{tabular}


Sumber: Hasil Penelitian, 2017

Dari hasil pengamatan yang dilakukan terhadap ekosistem hutan sibolangit. Banyaknya jenis organisme yang terdapat pada ekosistem hutan lebih beragam dibandingkan dengan ekosistem lainnya yang ada di sekitarnya. Hal ini dikarenakan aspek biotik dan abiotik dari masing-masing ekosistem. Dari aspek biotik pada ekosistem hutan lebih banyak terdapat tumbuh-tumbuhan, baik pohon maupun berbagai jenis ilalang atau rerumputan.

Dari aspek abiotik pada ekosistem hutan juga merupakan faktor penting yang mempengaruhi jenis organisme yang hidup di dalamnya, baik dari suhu, intensitas cahaya, ketinggian tempat, jenis tanah, $\mathrm{pH}$ tanah, kesuburan tanah, kelembapan, kemiringan, curah hujan, dan warna tanah.

Komponen abiotik ini sangat menentukan kelangsungan hidup suatu ekosistem, karena sangat mempengaruhi proses-proses biologis, kimia, maupun fisik pada ekosistem tersebut. Tiap-tiap organisme yang terdapat pada kedua ekosistem mempunyai peranannya masingmasing. Hal ini sesuai dengan pernyataan Indrianto (2006) yang menyatakan bahwa komponen ekosistem yang lengkap harus mencakup produsen, konsumen, pengurai, dan komponen abiotik. Sebagai produsen adalah tumbuhan hijau yang merupakan satu-satunya komponen ekosistem yang dapat mengikat energi matahari secara langsung dan diubah menjadi energi kimia dalam proses fotosintesis. Konsumen yang mengkonsumsi energi yang dihasilkan oleh produsen yang dibedakan menjadi makrokonsumen (herbivora, karnivora tingkat I, tingkat II, dan top-karnivora) dan mikrokonsumen (pengurai) yakni organisme perombak bahan dari organisme yang telah mati melalui proses immobilisasi dan mineralisasi sehingaa menjadi unsure hara yang siap dimanfaatkan oleh produsen.

Di Sibolangit terdapat beberapa ciri ciri daun tumbuhan yaitu : ada yang memiliki daun menyirip, daun menjadi dan daun yang panjang dan tidak terlalu lebar.
Namun dari setiap tanaman yang memiliki jenis daun yang sama memiliki perbedaan seperti tinggi tanaman tersebut dan jenis batang tumbuhan tersebut. Dan pada perbedaan ciri ciri batang, pada akhir arus sungai atau tepi hutan banyak terdapat tanaman tanaman pendek dan semakin ke dalam mengikuti asal sungai mulai ditemukan tanaman dengan batang kurus namun tinngi sama seperti bentuk pohon pada umumnya dan sepanjang arus sungai yang banyak terdapat bebatuan ditumbuhi lumut hijau. Semakin ke dalam hutan semakin deras aliran sungai dan semakin banyak dijumpai jenis tanaman kecil, lumut yang menempel pada dinding-dinding di sekitar pinggiran sungai. Kemudian terdapat juga pohon yang mempunyai batang lebih besar namun banyak di jumpai tanaman paku dengan berbagai bentuk. Tanaman berdaun lebar juga banyak ditemukan di dalam hutan semakin ke dalam hutan jenis tanaman semakin banyak dan lebat juga sudah mulai ditemukan jenis pohon yang berbatang besar.

Jenis hutan sibolangit ini bisa digolongkan dengan hutan hujan tropis dan keadaan tanah yang selalu lembab karena pengaruh arus sungai pada hutan. Namun pada hutan sibolangit tidak ditemukan jenis pohon yang mengasilkan jenis buah yang bisa dimakan melainkan tanaman liar dan pohon liar. Semakin tinggi dataran hutan maka akan semakin banyak jenis florra yang ditemukan dan semakin banyak jenis pohon berdaun lebat dan berbatang besar yang ditemui.

Jenis flora juga mempengaruhi ekosistem fauna di hutan ini. Semakin banyak pohon besar ditemui maka akan terdapat orang hutan yang tinggal di hutan tersebut karena pemenuhan makanan terdapat pada jenis tumbuhan yang semakin banyak.

Hasil penelitian pada daerah hutan sibolangit tepatnya di desa bandar baru kec. Sibolangit sumatera utara diukur dari ketinggian tempat . 
Tabel 2. Ciri vegetasi sesuai ketinggian

\begin{tabular}{|c|c|c|c|}
\hline \multirow[t]{2}{*}{ No. } & \multirow{2}{*}{$\begin{array}{l}\text { Ketinggian } \\
\text { tempat (MDPL) }\end{array}$} & \multicolumn{2}{|l|}{ Ciri ciri vegetasi (Flora) } \\
\hline & & Bentuk dan ukuran daun & $\begin{array}{l}\text { Karakteristik batang / } \\
\text { diameter pohon }\end{array}$ \\
\hline 1. & $743 \mathrm{~m}$. & Menyirip,/ sedang & $5-10 \mathrm{~cm}$ \\
\hline 2. & $850 \mathrm{~m}$. & Menyirip, memanjang. /sedang & $5-40 \mathrm{~cm}$ \\
\hline 3. & $883 \mathrm{~m}$. & Menyirip, memanjang, / kecil & $15-70 \mathrm{~cm}$, \\
\hline 4. & 901m. & $\begin{array}{l}\text { Menyirip, menjari, /kecil, sedang, tumbuhan } \\
\text { paku }\end{array}$ & $\begin{array}{ll}20-100 & \mathrm{~cm} \\
\text { tumbuhan } & \text { semak } \\
\text { belukar } & \end{array}$ \\
\hline 5. & $920 \mathrm{~m}$. & $\begin{array}{l}\text { Menyirip, menjari/ kecil, sedang, tumbuhan } \\
\text { paku }\end{array}$ & $\begin{array}{l}33-130 \mathrm{~cm}, \\
\text { tumbuhan paku, }\end{array}$ \\
\hline 6. & 950m. & $\begin{array}{l}\text { Menyirip, memanjang, lagak lebar, } \\
\text { tumbuhan paku }\end{array}$ & $\begin{array}{l}36-150 \mathrm{~cm}, \\
\text { tumbuhan paku, jenis }\end{array}$ \\
\hline 7. & $1000 \mathrm{~m}$. & Menyirip, memanjang/ lebar & $\begin{array}{l}50-60 \mathrm{~cm} \text {, tumbuhan } \\
\text { inang,jenis epifit }\end{array}$ \\
\hline 8. & $1050 \mathrm{~m}$. & Menyirip/kecil, lebar; memanjang & $\begin{array}{l}20-40 \mathrm{~cm} \text {, tumbuhan } \\
\text { inang, lumut }\end{array}$ \\
\hline 9. & $1100 \mathrm{~m}$. & Menyirip/ kecil; lebar ; memanjang & $\begin{array}{l}20-40 \mathrm{~cm}, \text { tumbuhan } \\
\text { inang }\end{array}$ \\
\hline 10 & $1130 \mathrm{~m}$. & $\begin{array}{l}\text { Menjari /lebar; menyirip, kecil, lebar } \\
\text {;menjari/ lebar }\end{array}$ & $\begin{array}{l}\text { 10- } 30 \mathrm{~cm} ., \text { tumbuhan } \\
\text { inang }\end{array}$ \\
\hline 11 & $1180 \mathrm{~m}$. & $\begin{array}{l}\text { Menyirip /kecil memanjang, menumpang } \\
\text { hidup pada tumbuhan inang. Melekat pada } \\
\text { tanah/ batuan }\end{array}$ & $\begin{array}{l}\text { 10- } 30 \mathrm{~cm} \text {, anggrek, } \\
\text { tumbuhan paku, lumut }\end{array}$ \\
\hline 12 & $1200 \mathrm{~m}$. & Menyirip/ kecil, melekat pada pohn/ tanah & $10-30 \mathrm{~cm}$, lumut \\
\hline 13 & $1300 \mathrm{~m}$. & $\begin{array}{l}\text { Melekat pada pohon/ tanah } \\
\text { menyipip/kecil, }\end{array}$ & $10-20 \mathrm{~cm}$, lumut \\
\hline
\end{tabular}

Sumber: Hasil Penelitian, 2017

Tabel 3. Klasifikasi Flora Sesuai Suhu dan Ketinggian

\begin{tabular}{|c|l|l|l|l|}
\hline \multirow{2}{*}{ No. } & \multirow{2}{*}{$\begin{array}{c}\text { Ketinggian } \\
\text { tempat } \\
\text { (MDPL) }\end{array}$} & $\begin{array}{c}\text { Suhu } \\
\text { (derajat) }\end{array}$ & \multicolumn{1}{|c|}{ Filum } & \multicolumn{1}{|c|}{ Kelas } \\
\cline { 4 - 5 } & $7430 \mathrm{~m}$. & $30^{\circ} \mathrm{C}$ & $\begin{array}{l}\text { Spermathophyta } \\
\text { (mendominasi), } \\
\text { pherydophyta, } \\
\text { bryophyta }\end{array}$ & $\begin{array}{l}\text { Gymnospermae } \\
\text { (mendominasi), } \\
\text { angyospermae, ptherophyta, } \\
\text { ricciocarpus sp }\end{array}$ \\
\hline 2. & $901 \mathrm{~m}$. & $22^{\circ} \mathrm{C}$ & $\begin{array}{l}\text { Spermathophyta } \\
\text { (mendominasi), } \\
\text { pherydophyta, } \\
\text { bryophyta }\end{array}$ & $\begin{array}{l}\text { Gymnospermae } \\
\text { angyospermae } \\
\text { (mendominasi), ptherophyta, } \\
\text { ricciocarpus sp, lycophyta }\end{array}$ \\
\hline 3. & $1000 \mathrm{~m}$. & $17,5^{\circ} \mathrm{C}$ & $\begin{array}{l}\text { pherydophyta } \\
\text { (mendominasi), } \\
\text { Spermathophyta, } \\
\text { bryophyta }\end{array}$ & $\begin{array}{l}\text { Pherophyta dan sphenphyta } \\
\text { serta } \\
\text { (mendominasi), } \\
\text { gymnospermae } \\
\text { angyospermae, bryophyta }\end{array}$ \\
\hline 4. & $1180 \mathrm{~m}$. & $17^{\circ} \mathrm{C}$ & $\begin{array}{l}\text { pherydophyta } \\
\text { (mendominasi), }\end{array}$ & $\begin{array}{l}\text { Pherophyta dan sphenphyta } \\
\text { serta }\end{array}$ \\
\hline
\end{tabular}




\begin{tabular}{|c|l|l|l|l|}
\hline & & & $\begin{array}{l}\text { Spermathophyta, } \\
\text { bryophyta }\end{array}$ & $\begin{array}{l}\text { (mendominasi), } \\
\text { angyospermae, bryophyta, } \\
\text { hepatophyta }\end{array}$ \\
\hline 5. & $1200 \mathrm{~m}$. & $12^{\circ} \mathrm{C}$ & $\begin{array}{l}\text { bryophyta } \\
\text { (mendominasi), } \\
\text { pherydophyta } \\
\text { Spermathophyta }\end{array}$ & $\begin{array}{l}\text { Bryophyta dan hepatophyta } \\
\text { serta rthocerophyta } \\
\text { (mendominasi), } \\
\text { ptheropchyta, sphenophyta, } \\
\text { lycophyta, angyosmpermae }\end{array}$ \\
\hline 6. & $1300 \mathrm{~m}$. & $12^{\circ} \mathrm{C}$ & $\begin{array}{l}\text { bryophyta } \\
\text { (mendominasi), } \\
\text { pherydophyta } \\
\text { Spermathophyta } \\
\text { fryophyta dan hepatophyta } \\
\text { serta rthocerophyta } \\
\text { (mendominasi), } \\
\text { ptheropchyta, sphenophyta, } \\
\text { lycophyta, angyosmpermae }\end{array}$ \\
\hline
\end{tabular}

Sumber: Hasil Penelitian, 2017

\section{DAFTAR PUSTAKA}

Ellenberg, D., \& Mueller-Dombois, D. (1974). Aims and methods of vegetation ecology. New York, NY: Wiley.

Damayanti, A. (2013). Analisis Zone Agroekologi untuk Strategi Pengelolaan DAS Berkelanjutan. JURNAL GEOGRAFI, 5(1), 1-16.

Fahreza, W., \& Restu, R. (2016). ANALISIS RUANG TERBUKA HIJAU PERUMAHAN NASIONAL DI KOTA MEDAN. JURNAL GEOGRAFI, 8(2), 197-207.

Lubis, D. P. (2011). Pengaruh Perubahan Iklim Terhadap Keanekaragaman
Hayati di Indonesia. JURNAL GEOGRAFI, 3(2), 107-117.

Kusumo, A., Nur Bambang, A., \& Izzati, M. (2016). Struktur vegetasi kawasan hutan alam dan hutan rerdegradasi di Taman Nasional Tesso Nilo. Jurnal IImu Lingkungan Undip, 14(1), 19-26.

Widodo, S. (1980). Pengantar Politik Pertanian. Fakultas Pertanian Universitas Gadjah Mada, Yogyakarta.

Wiersum, K. F. (1979). Introduction to Principles of Forest Hydrology and Erosion: With Special Reference to Indonesia. Universitas Padjadjaran, Lembaga Ekologi. 